\title{
Nanocrystallization of Coarse Primary Phases in Al- and Mg-Based Alloys Induced by HCPEB Treatment
}

\author{
Gao Bo, He Jidong, Tu Ganfeng, and Hu Liang \\ School of Materials and Metallurgy, Northeastern University, Shenyang 110004, China \\ Correspondence should be addressed to Gao Bo; surfgao@yahoo.com.cn
}

Received 12 April 2013; Accepted 26 May 2013

Academic Editor: Yogendra Mishra

Copyright ( 2013 Gao Bo et al. This is an open access article distributed under the Creative Commons Attribution License, which permits unrestricted use, distribution, and reproduction in any medium, provided the original work is properly cited.

\begin{abstract}
This paper reports on a phenomenon associated with high-current pulsed electron beam (HCPEB) treatment: surface nanocrystallization of coarse primary phase in hypereutectic All7.5Si and quasicrystal alloys after multiple pulses of HCPEB irradiation. The HCPEB treatment induces superfast heating and diffusion of alloying elements and heterogeneous nucleation in a melting solution, followed by rapid solidification and cooling of the material surfaces. Consequently, nanostructured surface layers can be achieved easily. Nano-Si phase and nano-quasicrystal phase formation on the modified surface layer of hypereutectic All7.5Si alloy and quasicrystal alloy $\left(\mathrm{Mg}_{37} \mathrm{Zn}_{60} \mathrm{Y}_{3}\right)$ show a potential for surface nanocrystallization of materials with enhanced properties by HCPEB treatment.
\end{abstract}

\section{Introduction}

Nanomaterials are typically characterized by ultrafine grains ranging from $1 \mathrm{~nm}$ to $100 \mathrm{~nm}$ (at least one dimension) [1, 2]. Nanomaterials fundamentally exhibit unique properties such as increased strength/hardness, enhanced diffusivity, improved toughness/ductility, reduced elastic modulus, enhanced thermal expansion coefficient, and superior soft magnetic properties [3] compared with conventional coarsegrained materials.

The high-current pulsed electron beam (HCPEB) technique is a novel method [4-10] used to modify the surface of a material. This technique is simple, reliable, and has been proven highly efficient for decades. The electron beam causes intense and superfast melting as well as evaporation and solidification on the surface of target materials, thereby creating thermal stress and shockwaves. Consequently, nonequilibrium phase and structural transformations occur in the beam-affected zone, including a metastable structure or phase states on the surface layer $[11,12]$. The combination of influencing factors unique to HCPEB treatment can induce the formation of nanocrystalline layers in the near-surface regions of metallic materials [10-12]. The present study reports on the nanocrystallization of coarse primary phases in Al- and Mg-based alloys induced by HCPEB.

\section{Experimental Procedures}

2.1. Starting Materials and HCPEB Treatment. The starting materials consisted of $\mathrm{Mg}_{67} \mathrm{Zn}_{30} \mathrm{Y}_{3}$ quasicrystal alloy (with a chemical composition of $\mathrm{Zn}$ (50.86 wt\%), Y (7.02 wt\%), and $\mathrm{Mg}$ balance) and hypereutectic Al-17.5Si alloy (with a chemical composition of Si (17.5 wt\%) and Al balance). Prior to HCPEB treatment, the samples were cut into $\Phi 10 \mathrm{~mm} \times 9 \mathrm{~cm}$ cylinders with surfaces mechanically polished and washed with absolute ethyl alcohol. The sample surfaces were then treated on a Nadezhda-2-type HCPEB system under the following conditions: accelerating voltage, $23 \mathrm{kV}$; energy density, $3 \mathrm{~J} / \mathrm{cm}^{2}$; pulse duration, $\sim 1 \mu \mathrm{s}$; and number of pulses, 2,10 , and 15 for the quasicrystal alloy $\mathrm{Mg}_{67} \mathrm{Zn}_{30} \mathrm{Y}_{3}$ and 5, 15, and 100 for the hypereutectic Al-17.5Si alloy.

2.2. Microstructural Analysis. The sample surface and crosssectional morphologies were analyzed using a field-emission gun scanning electron microscope (FEG-SEM) (Jeol JSM 


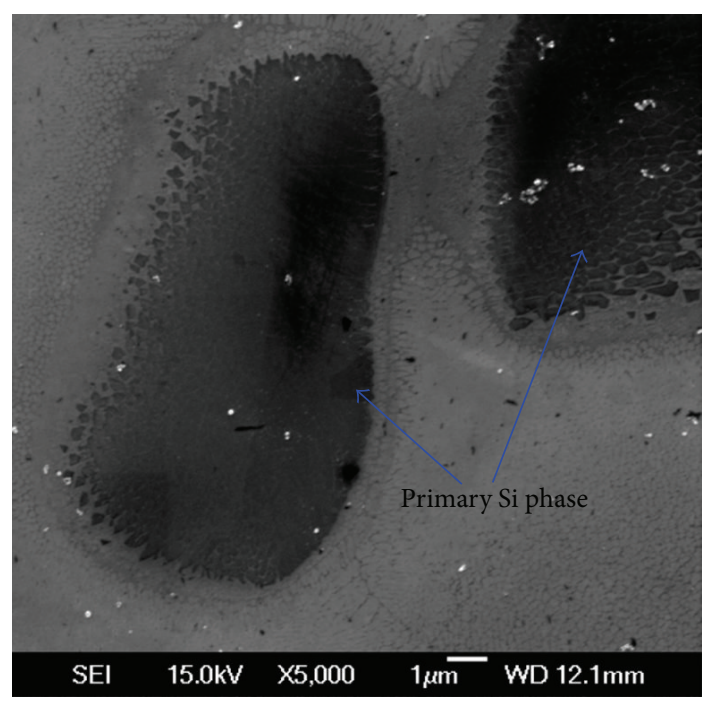

(a)

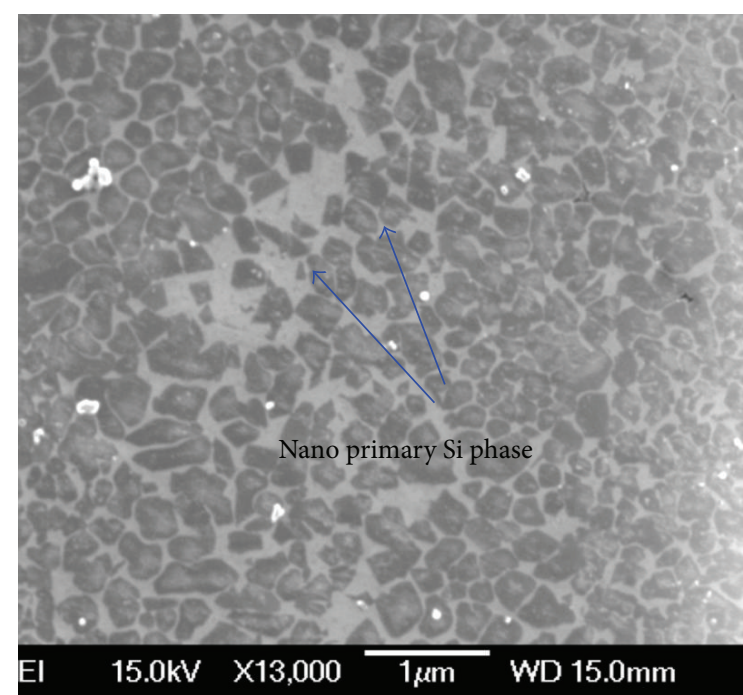

(b)

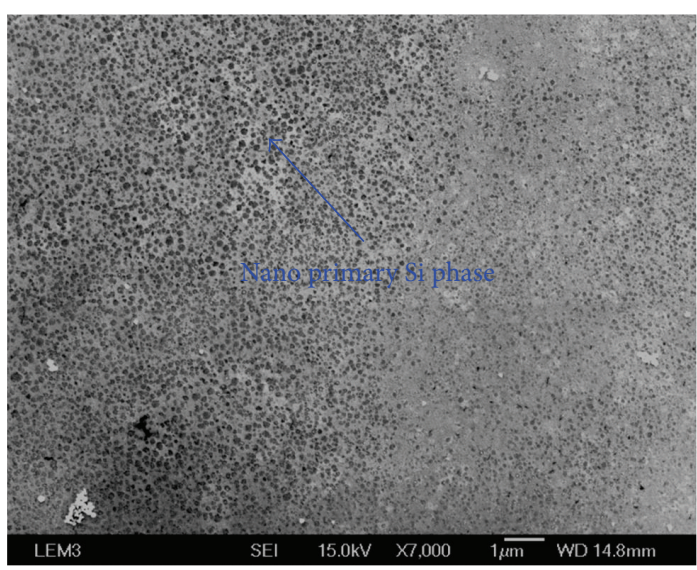

(c)

FIGURE 1: The evolution of the coarse primary Si phase in hypereutectic All7.5Si alloy with number pulse of HCPEB treatment of hypereutectic Al-17.5Si alloy ((a) 5 pulse, (b) 15 pulse, and (c) 100 pulse).

$6500 \mathrm{~F})$ with an electron backscatter diffraction acquisition camera and Channel 5 software. The beam control mode was applied for automatic orientation mapping with a step size of $0.04 \mu \mathrm{m}$. Thin films for transmission electron microscopy (TEM) were prepared by grinding, dimpling, and ionbeam thinning, and the microstructure characteristics were observed using a transmission electron microscope (FEITecnai G220).

2.3. Wear Resistance Measurement. The dry wear tests for the two alloys were performed by an MG-2000 type pinon-disc machine at room temperature of $25^{\circ} \mathrm{C}$. The sample size was $6 \mathrm{~mm}$-diameter and $12 \mathrm{~mm}$-length. The stainless steel (1Cr18Ni9) was acted as sliding counterpart disc in wear tests, whose surface hardness and roughness were $192 \mathrm{HV}$ and $1 \mu \mathrm{m}$ $\left(R_{a}\right)$, respectively. The applied load was $10 \mathrm{~N}$. Sliding speed and distance were kept at $0.8 \mathrm{~m} / \mathrm{s}$ and $0.096 \mathrm{~km}$.

\section{Results}

3.1. Nano-Si Phase in Irradiated Hypereutectic Al17.5Si Alloy. Figure 1 shows the evolution of the coarse primary Si phase in hypereutectic Al17.5Si alloy with the number of pulses of HCPEB treatment. Figure 1(a) presents the typical SEM micrograph taken on a 5-pulsed sample. The figure shows that the size of the coarse primary Si phase is approximately $20 \mu \mathrm{m}$, and the edge of the primary Si phase begins to melt and form fine Si crystals with a size of $500 \mathrm{~nm}$. In the Al-rich zone outside the primary Si phase, the special nanocellular structure is formed. Figure 1(b) presents a typical SEM micrograph of the Si-rich zone taken on a 15-pulsed sample. As indicated in the figure, the coarse primary Si phase disappears completely, and numerous fine, dispersive nanoprimary $\mathrm{Si}$ phases are formed, with sizes ranging from $200 \mathrm{~nm}$ to $300 \mathrm{~nm}$. Figure 1(c) shows a typical SEM micrograph of the Si-rich zone on a 100-pulsed sample. The figure reveals that the coarse primary $\mathrm{Si}$ phase is refined further, with sizes 


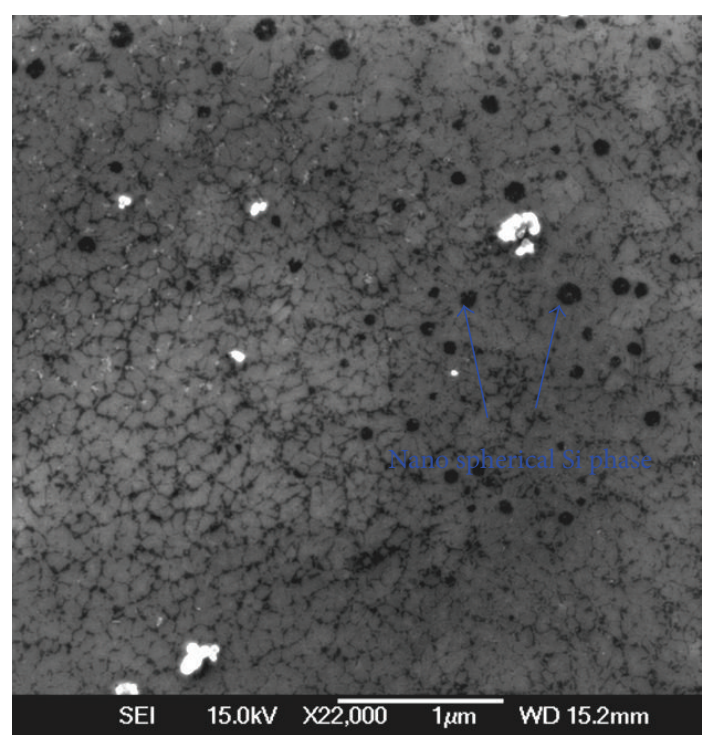

FIGURE 2: High magnification SEM image of primary Si phase in HCPEB-treated hypereutectic Al-17.5Si alloy under energy density of $3 \mathrm{~J} / \mathrm{cm}^{2}$ and 100 pulses.

ranging from $60 \mathrm{~nm}$ to $120 \mathrm{~nm}$. The morphology of the nano primary phase almost resembles a spherical shape. Figure 1 shows that the size of the primary $\mathrm{Si}$ phase is refined in the range of $20 \mu \mathrm{m}$ to $30 \mu \mathrm{m}$ in the initial sample, whereas the size of the 100-pulsed sample is refined in the range of $60 \mathrm{~nm}$ to $120 \mathrm{~nm}$. We can deduce that with the increase in the number of pulses, the coarse primary Si phase underwent multiple melting, diffusion, and solidification and was then refined step by step to sizes ranging from $60 \mathrm{~nm}$ to $120 \mathrm{~nm}$.

Figure 2 reveals a high-magnification FEG-SEM image of the 100 pulses treated with Al-17.5Si alloy. As indicated in the figure, a number of ultrafine and dispersive spherical $\mathrm{Si}$ crystals are formed in the Si-rich zone and surrounded by $\alpha(\mathrm{Al})$ cells. The $\alpha(\mathrm{Al})$ cells grow on top of the nano-Si crystals, indicating that nano-Si crystals can function as superfine heterogeneous nucleation sites for the $\alpha(\mathrm{Al})$ phase. A detailed discussion is provided in the subsequent section.

3.2. Nano-Quasicrystal Phase in Irradiated $M g_{67}-Z_{30}-Y_{3}$ Quasicrystal Alloy. Figure 3 presents the SEM back-scattered electron images of the $\mathrm{Mg}_{67} \mathrm{Zn}_{30} \mathrm{Y}_{3}$ quasicrystal alloy in its initial state and after HCPEB treatment for 2 and 15 pulses. Figure 1(a) shows the initial structure of the $\mathrm{Mg}_{67} \mathrm{Zn}_{30} \mathrm{Y}_{3}$ quasicrystal alloy, composed of the following: a gray matrix phase, a black dendrite phase, and a white petal-shaped phase. Energy-dispersive X-ray spectroscopy (EDS) analysis demonstrates that the chemical composition of the gray

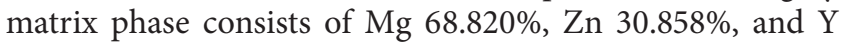
$0.322 \%$. The globular black dendrite is composed of $\mathrm{Mg}$ $45.088 \%, \mathrm{Zn} 54.080 \%$, and Y $0.832 \%$. In Figure 1(a), the most prominent characteristic of the initial structure is the formation of the white petal-shaped phase, consisting of $\mathrm{Mg}$ $37.496 \%$, Zn 53.022\%, and Y 9.482\%. This phase is represented by the chemical formula $\mathrm{Mg}_{37} \mathrm{Zn}_{53} \mathrm{Y}_{10}$, which deviates from the quasicrystal $\mathrm{Mg}_{30} \mathrm{Zn}_{60} \mathrm{Y}_{10}$ of the standard ternary $\mathrm{Mg}$ - $\mathrm{Zn}$ $\mathrm{Y}$ alloy reported in [13]. The white petal-shaped phase is a quasicrystal phase confirmed by TEM detection [14].

As shown in Figure 3(b), the surfaces of $\mathrm{Mg}_{67} \mathrm{Zn}_{30} \mathrm{Y}_{3}$ quasicrystal alloys are repeatedly melted and solidified owing to multiple HCPEB treatments (two pulses). Consequently, the phase boundaries between different phases become indistinct, and a petal-shaped white phase in the initial structure is uniformly distributed in the matrix after HCPEB irradiation. Figure 3(c) shows the top-surface microstructure characteristics of $\mathrm{Mg}_{67} \mathrm{Zn}_{30} \mathrm{Y}_{3}$ after a 15-pulsed treatment. Compared with that of the sample after a two-pulsed treatment, the chemical composition distribution becomes more uniform, with the phase boundary becoming indistinct. By EDS analysis, the dispersed white phase is determined to consist of $\mathrm{Mg} 58.139 \%$, Zn 34.655\%, and Y 7.206\%. Under HCPEB treatment, the Mg element in the matrix phase and dendrite phase diffuses into a white phase, whereas $\mathrm{Zn}$ and $\mathrm{Y}$ elements enriched in the white phase diffuse outward. HCPEB irradiation leads to the interdiffusion of alloying elements; consequently, the chemical composition of the treated surface layer exhibits a homogeneous distribution. Simultaneously, the size of the petal quasicrystal phase becomes significantly refined after multiple irradiations. The size and morphology of the quasicrystal phase are analyzed by TEM.

Figures 4(a) and 4(b) present a TEM bright field image of 10-pulse treated $\mathrm{Mg}_{67} \mathrm{Zn}_{30} \mathrm{Y}_{3}$ and its corresponding selected area (electron) diffraction pattern (diffraction rings) [14]. After the 10-pulse treatment, numerous nanosized particles with grain sizes ranging from $10 \mathrm{~nm}$ to $30 \mathrm{~nm}$ are uniformly distributed on the surface layer. To determine the crystalline structure of the nanophase, the interplanar spacing values corresponding to each diffraction ring were calculated. Compared with the interplanar spacing $\left(\mathrm{d}_{\text {stan }}\right)$ values of the acknowledged quasicrystal $\mathrm{Mg}_{3} \mathrm{Zn}_{6} \mathrm{Y}$, the relative errors of all calculated results, except for one, are within 5\%. Thus, the dispersed metastable nanocrystalline phase is a quasicrystal phase $\mathrm{Mg}_{3} \mathrm{Zn}_{6} \mathrm{Y}$, indicating that a nanostructured quasicrystal layer is obtained by the action of electron beam.

3.3. Improvement in Wear Resistance. The weight loss of the Al-17.5Si and the $\mathrm{Mg}_{67} \mathrm{Zn}_{30} \mathrm{Y}_{3}$ quasicrystal alloys was determined before and after the HCPEB treatment. The results are shown in Figure 5. For the Al-17.5Si alloy, weight loss was reduced from $1.3 \times 10^{-3} \mathrm{~g}$ of the initial sample to $0.2 \times 10^{-3} \mathrm{~g}$ of the sample treated with 15 pulses, indicating a significant improvement in the wear resistance of the Al-17.5Si alloy after HCPEB treatment. The relative wear resistance was enhanced by a factor of 6.5. The weight loss of the $\mathrm{Mg}_{67} \mathrm{Zn}_{30} \mathrm{Y}_{3}$ quasicrystal alloy sample was $1.7 \times 10^{-3} \mathrm{~g}$ before the HCPEB treatment, which was reduced to $0.8 \times 10^{-3} \mathrm{~g}$ after the 15-pulse treatment. Consequently, the relative wear resistance was improved by a factor of 2.1, which can be attributed to the formation of a supersaturated solid solution of $\alpha(\mathrm{Mg})$ and the grain refinement of the melted layer. Nanocrystallization induced by HCPEB surface treatment is known to contribute significantly to the improvement of wear 


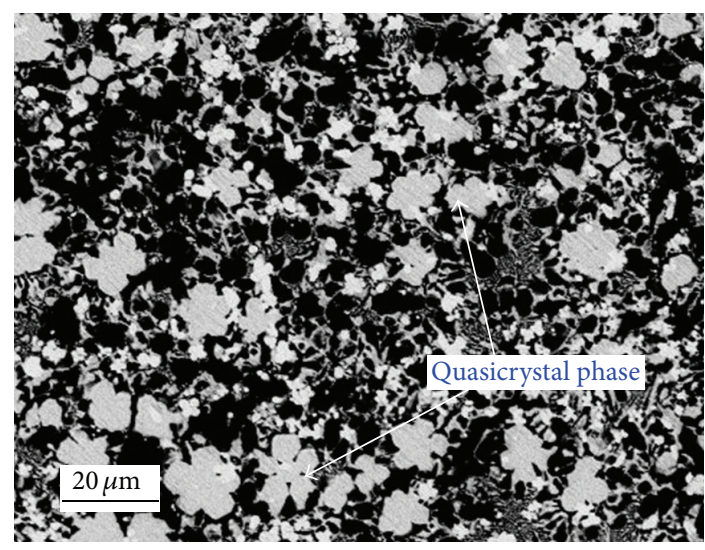

(a)

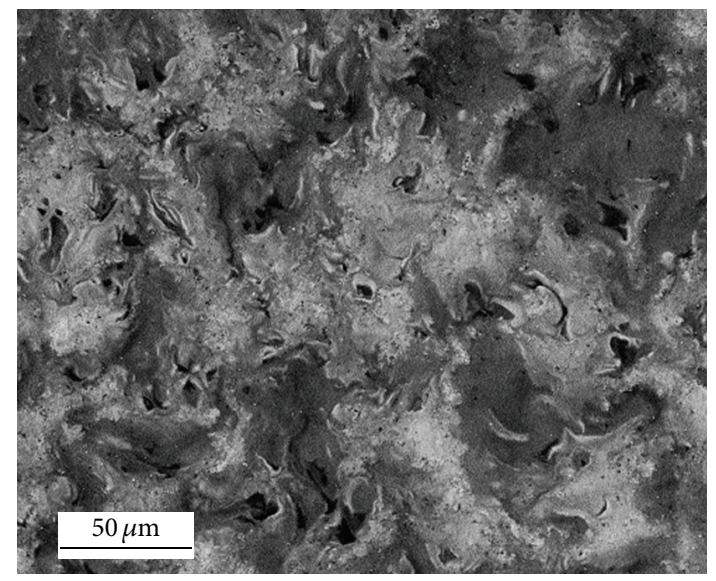

(b)

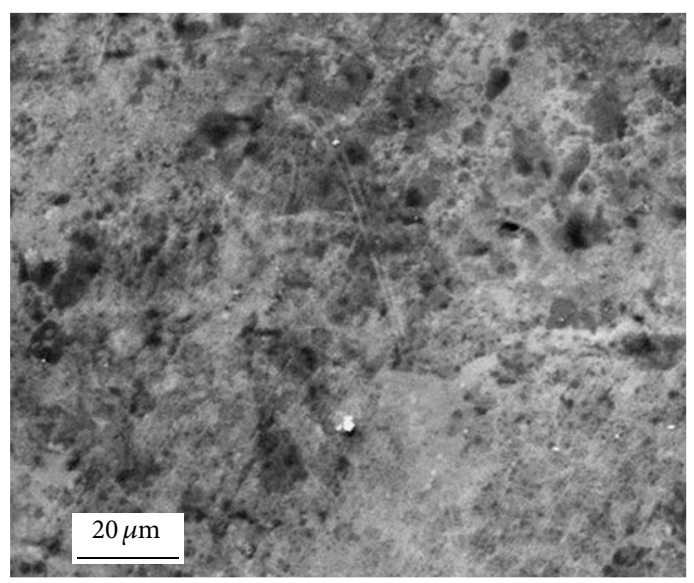

(c)

FIGURE 3: Surface SEM BSE images of $\mathrm{Mg}_{67} \mathrm{Zn}_{30} \mathrm{Y}_{3}$ quasicrystal alloy in initial state (a) and after HCPEB treatment for 2 pulses (b) and 15 pulses (c).

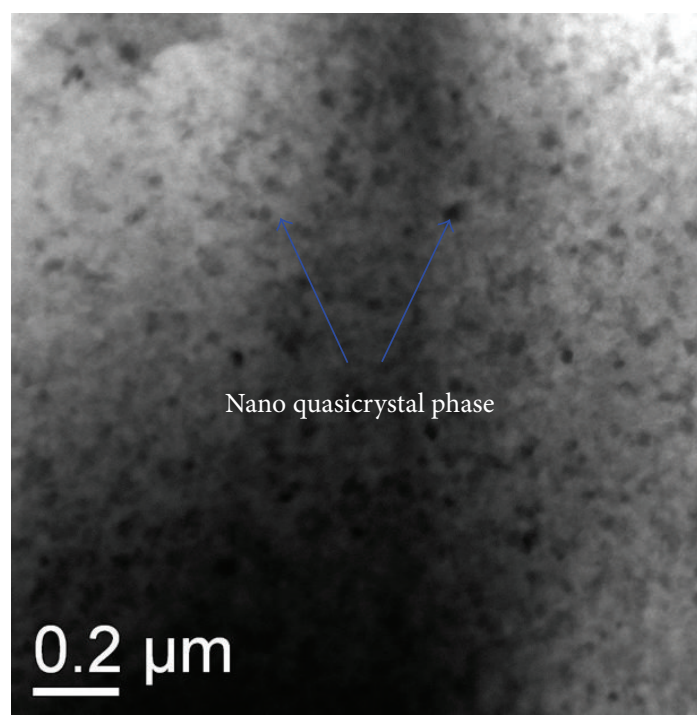

(a)

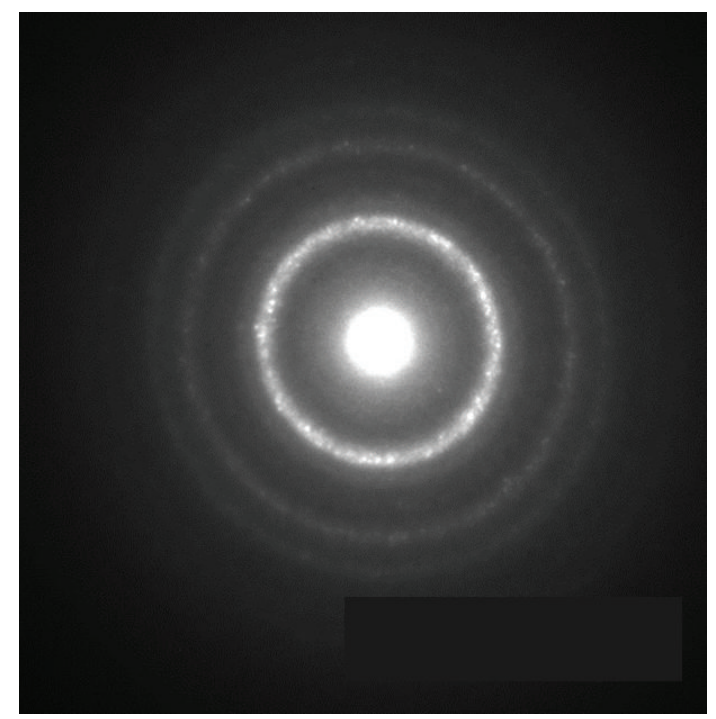

(b)

FIGURE 4: TEM bright field image of 10 -pulse treated $\mathrm{Mg}_{67} \mathrm{Zn}_{30} \mathrm{Y}_{3}$ (a) and corresponding SAED pattern (b). 


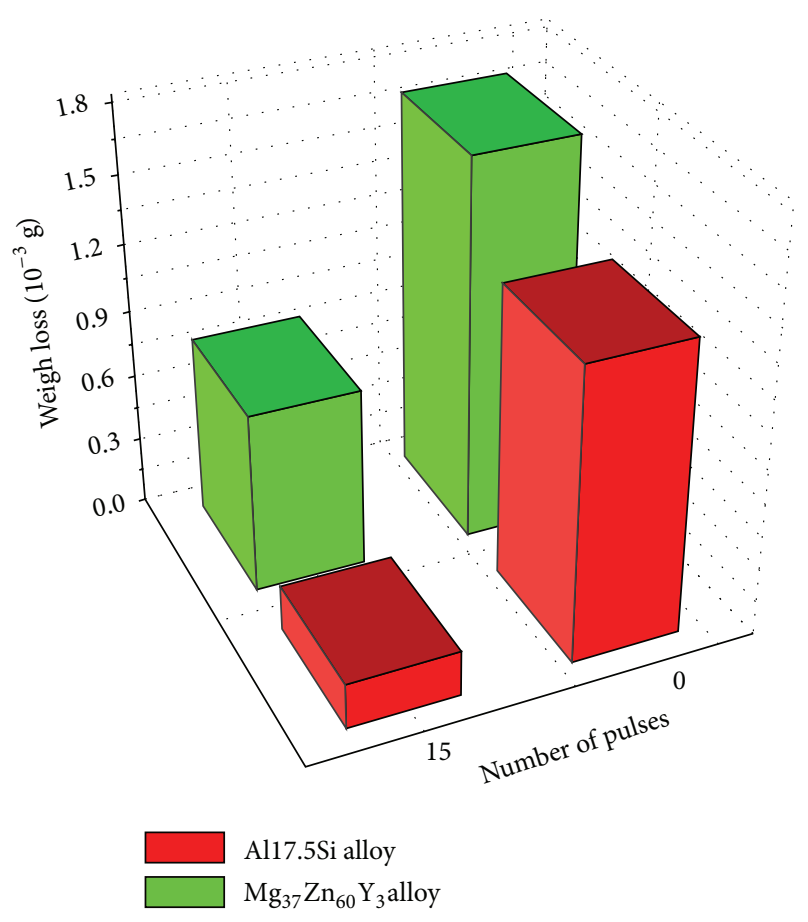

FIgURE 5: Weigh loss of Al17.5Si and $\mathrm{Mg}_{37} \mathrm{Zn}_{60} \mathrm{Y}_{3}$ alloys before and after HCPEB treatment.

resistance of $\mathrm{Al}-17.5 \mathrm{Si}$ and $\mathrm{ZK} 60-1 \mathrm{Y} \mathrm{Mg}_{67} \mathrm{Zn}_{30} \mathrm{Y}_{3}$ quasicrystal alloys.

\section{Discussion}

The nano primary $\mathrm{Si}$ phase in the hypereutectic Al-17.5 Si alloy is formed during the rapid solidification of the HCPEB treatment. Therefore, several factors that affect the nucleation and the growth of the Si influence the formation of the nanostructure. Figure 2 presents the microstructure characteristics of the zone near the boundary between the Sirich and Al-rich zones of the 100-pulse treated sample. The microstructures observed in Figure 2 suggest the following description of the HCPEB treatment process. First, in the heating and melting state, the Si element diffuses from the primary Si phase to the edge of the Si-rich zone; however, the $\mathrm{Al}$ element diffuses toward the opposite direction. Second, in the solidification state, the Si crystals nucleate from the supersaturated melted solution and grow into the undercooled melt of the environment. The Si crystals reject the $\mathrm{Al}$ until the local concentration is sufficient to nucleate the $\alpha(\mathrm{Al})$ phase. The $\alpha(\mathrm{Al})$ phase nucleates on the special crystal plane and surrounds the Si particles, thereby preventing the growth of the Si phase. With an increase in the number of pulses, the Si element continually diffuses from the coarse phase and forms a new nano-Si phase in the melted solution. Consequently, the size of the primary Si phase decreases, thereby forming an extremely fine nanodispersive Si phase after 100-pulsed treatment. Meanwhile, HCPEB irradiation exerts a similar effect on the refinement of the coarse petalshaped quasicrystal phase $\left(\mathrm{Mg}_{3} \mathrm{Zn}_{6} \mathrm{Y}\right)$; after multiple-pulse treatments, the size of the coarse quasicrystal phase reaches the $10 \mathrm{~nm}$ to $30 \mathrm{~nm}$ range by TEM analysis. Naturally, the fine primary Si phase and quasicrystal phase contributes to the enhanced tribological properties of hypereutectic Al17.5Si alloy and quasicrystal alloy $\mathrm{Mg}_{67} \mathrm{Zn}_{30} \mathrm{Y}_{3}$.

\section{Conclusions}

This study demonstrates that the surface nanocrystallization of the primary $\mathrm{Si}$ phase in hypereutectic Al17.5Si alloy and quasicrystal phase $\left(\mathrm{Mg}_{3} \mathrm{Zn}_{6} \mathrm{Y}\right)$ in quasicrystal alloy $\left(\mathrm{Mg}_{67} \mathrm{Zn}_{30} \mathrm{Y}_{3}\right)$ is induced by HCPEB irradiation. In both cases, nanograined primary phases are formed on the materials after a sufficient number of pulses. The results indicate a strong potential for surface nanocrystallization of the coarse primary phase in alloys treated by HCPEB, and the nanocrystallization surfaces of the two alloys exhibit very high wear resistance compared with that of initial samples. The mechanisms were identified to produce nanostructures from the melted liquid by taking advantage of the rapid thermal cycle and the diffusion of alloying elements, as well as the heterogeneous nucleation generated by the HCPEB process.

\section{Acknowledgments}

This study is supported by the Natural Science Foundation of Shenyang City (F12-277-1-55) and the Program for Excellent Talents in Liaoning Province (LJQ2012021). The authors gratefully acknowledge the help of Dr Yi Hao and Shiwei Li.

\section{References}

[1] N. R. Tao, M. L. Sui, J. Lu, and K. Lua, "Surface nanocrystallization of iron induced by ultrasonic shot peening," Nanostructured Materials, vol. 11, no. 4, pp. 433-440, 1999.

[2] K. Lu and J. Lu, "Surface nanocrystallization (SNC) of metallic materials-presentation of the concept behind a new approach," Journal of Materials Science and Technology, vol. 15, no. 3, pp. 193-197, 1999.

[3] C. Suryanarayana, "Nanocrystalline materials," International Materials Reviews, vol. 40, no. 2, pp. 41-64, 1995.

[4] B. Gao, S. Hao, J. Zou, W. Wu, G. Tu, and C. Dong, "Effect of high current pulsed electron beam treatment on surface microstructure and wear and corrosion resistance of an AZ91HP magnesium alloy," Surface and Coatings Technology, vol. 201, no. 14, pp. 6297-6303, 2007.

[5] Y. Hao, B. Gao, G. F. Tu, S. W. Li, S. Z. Hao, and C. Dong, "Surface modification of Al-20Si alloy by high current pulsed electron beam," Applied Surface Science, vol. 257, no. 9, pp. 39133919, 2011.

[6] J. X. Zou, K. M. Zhang, S. Z. Hao, C. Dong, and T. Grosdidier, "Mechanisms of hardening, wear and corrosion improvement of $316 \mathrm{~L}$ stainless steel by low energy high current pulsed electron beam surface treatment," Thin Solid Films, vol. 519, no. 4, pp. 1404-1415, 2010.

[7] Y. Qin, C. Dong, Z. F. Song et al., "Deep modification of materials by thermal stress wave generated by irradiation of high-current pulsed electron beams," Journal of Vacuum Science \& Technology A, vol. 23, pp. 430-435, 2009. 
[8] S. Hao, B. Gao, A. Wu et al., "Surface modification of steels and magnesium alloy by high current pulsed electron beam," Nuclear Instruments and Methods in Physics Research B, vol. 240, no. 3, pp. 646-652, 2005.

[9] Q. F. Guan, H. Zou, G. T. Zou et al., "Surface nanostructure and amorphous state of a low carbon steel induced by high-current pulsed electron beam," Surface and Coatings Technology, vol. 196, no. 1-3, pp. 145-149, 2005.

[10] Y. Hao, B. Gao, G. F. Tu, S. W. Li, C. Dong, and Z. G. Zhang, "Improved wear resistance of Al-15Si alloy with a high current pulsed electron beam treatment," Nuclear Instruments and Methods in Physics ResearchB, vol. 269, no. 13, pp. 14991505, 2011.

[11] B. Gao, Y. Hao, G. F. Tu, and W. Y. Wu, "Study on nanostructures induced by high current pulsed electron beam treatment," Journal of Nanomaterials, vol. 2012, Article ID 480482, 5 pages, 2012.

[12] K. M. Zhang, J. X. Zou, and T. Grosdidier, "Nanostructure formations and improvement in corrosion resistance of steels by means of pulsed electron beam surface treatment," Journal of Nanomaterials, vol. 2013, Article ID 78568, 8 pages, 2013.

[13] A. P. Tsai, A. Niikura, A. Inoue, and T. Masumoto, "Stoichiometric icosahedral phase in the Zn-Mg-Y system," Journal of Materials Research, vol. 12, no. 6, pp. 1468-1471, 1997.

[14] B. Gao, Y. Hao, G. F. Tu et al., "Surface modification of $\mathrm{Mg}_{67^{-}}$ $\mathrm{Zn}_{30}-\mathrm{Y}_{3}$ quasicrystal alloy by high current pulsed electronbeam," Surface and Coatings Technology. In press. 

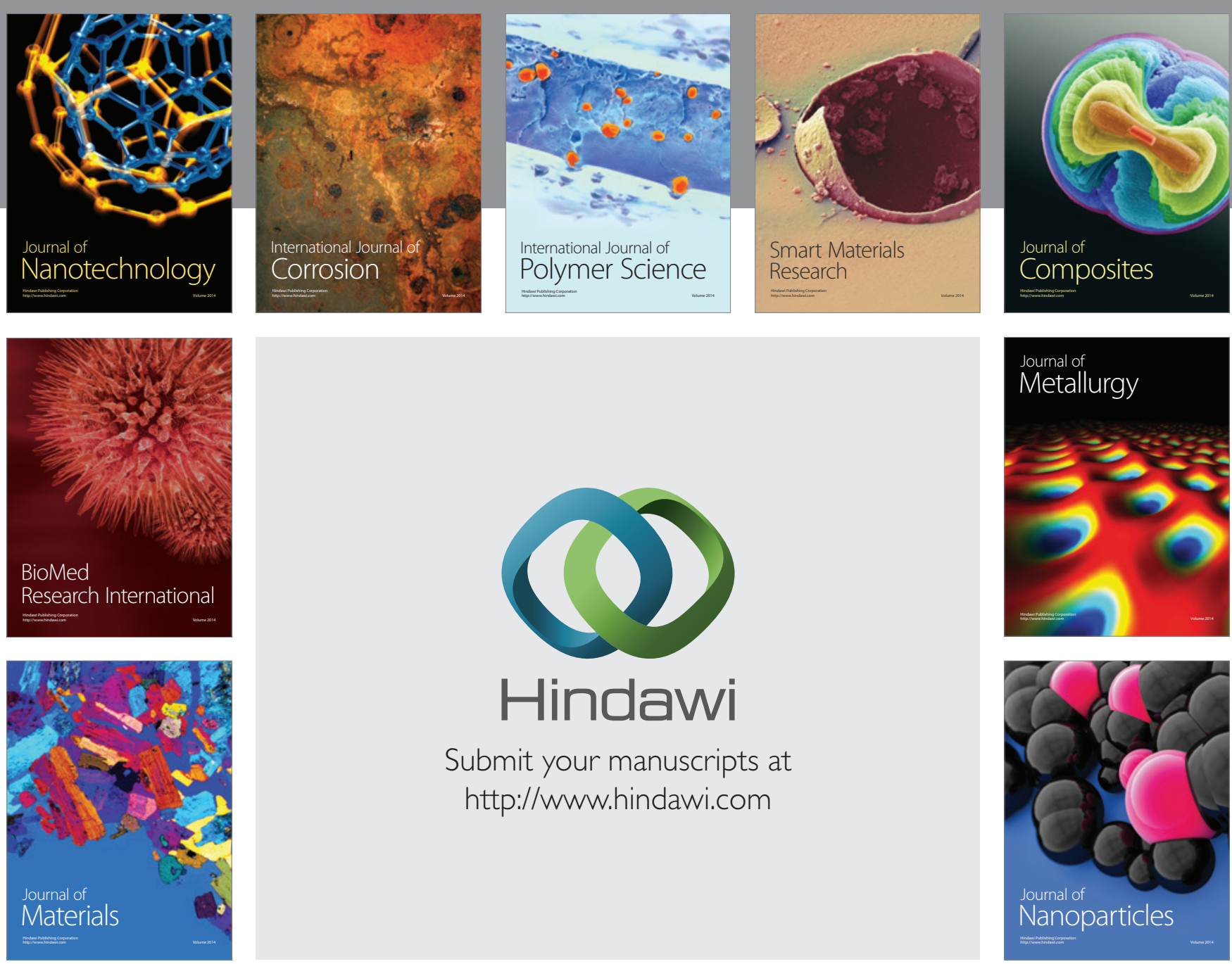

Submit your manuscripts at http://www.hindawi.com
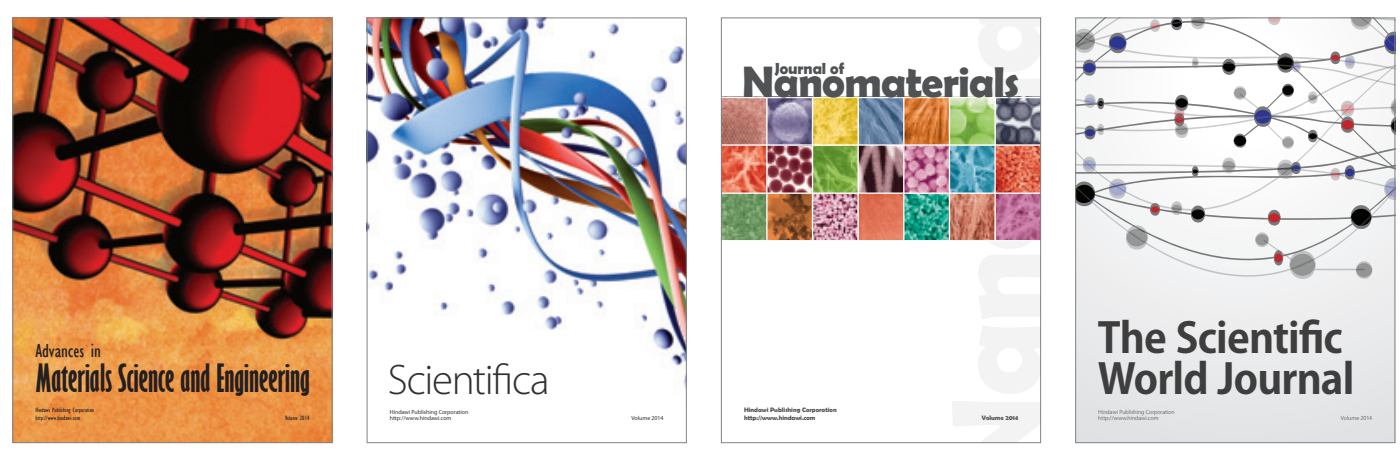

\section{The Scientific World Journal}
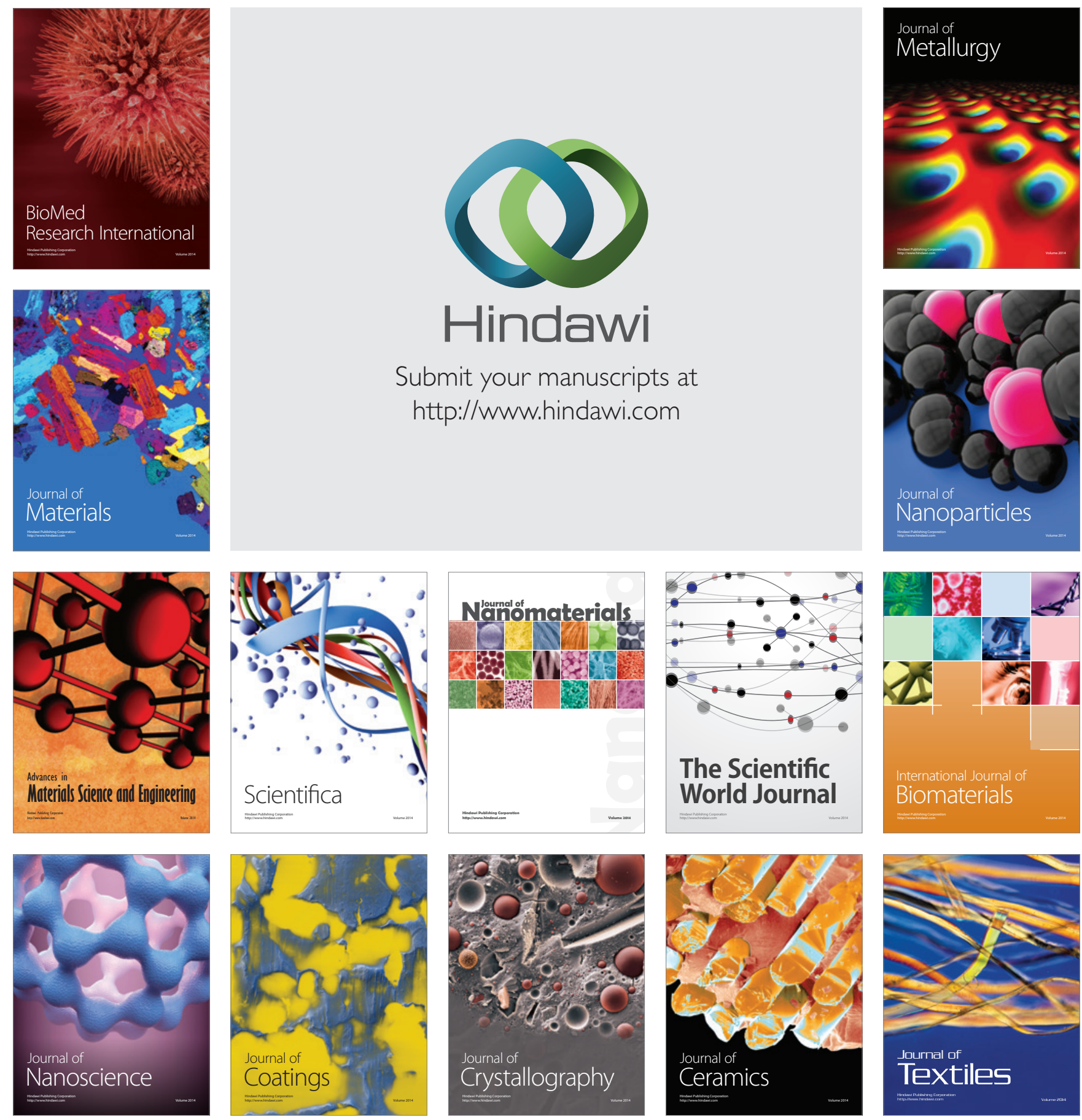